
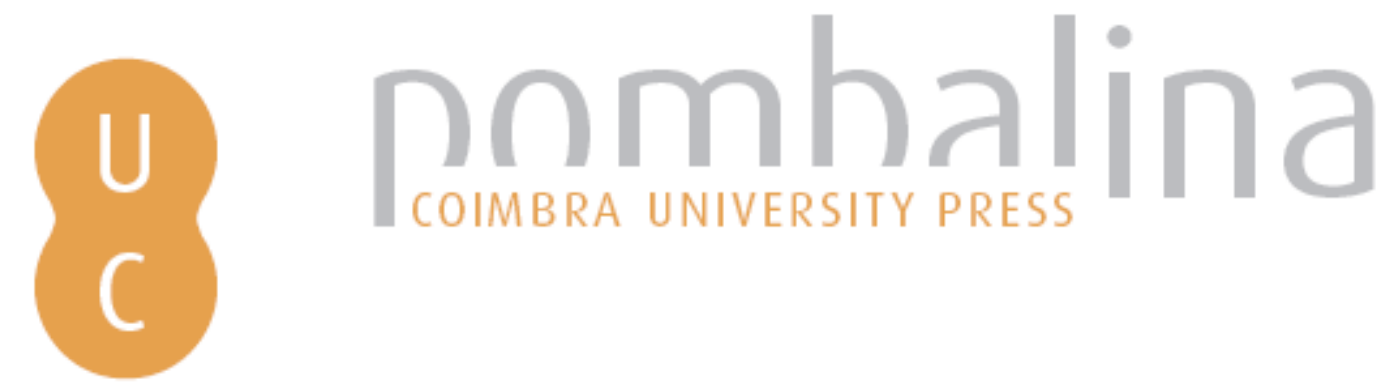

\title{
Atuação da ABEBD na evolução do currículo de graduação em biblioteconomia no Brasil, entre os anos 1967 e 2000
}

Autor(es): $\quad$ Souza, Francisco das Chagas de

Publicado por: Imprensa da Universidade de Coimbra

URL

persistente: $\quad$ URI:http://hdl.handle.net/10316.2/31926

DOI: $\quad$ DOI:http://dx.doi.org/10.14195/978-989-26-0319-3_30

Accessed : $\quad$ 26-Apr-2023 08:50:47

A navegação consulta e descarregamento dos títulos inseridos nas Bibliotecas Digitais UC Digitalis, UC Pombalina e UC Impactum, pressupõem a aceitação plena e sem reservas dos Termos e Condições de Uso destas Bibliotecas Digitais, disponíveis em https://digitalis.uc.pt/pt-pt/termos.

Conforme exposto nos referidos Termos e Condições de Uso, o descarregamento de títulos de acesso restrito requer uma licença válida de autorização devendo o utilizador aceder ao(s) documento(s) a partir de um endereço de IP da instituição detentora da supramencionada licença.

Ao utilizador é apenas permitido o descarregamento para uso pessoal, pelo que o emprego do(s) título(s) descarregado(s) para outro fim, designadamente comercial, carece de autorização do respetivo autor ou editor da obra.

Na medida em que todas as obras da UC Digitalis se encontram protegidas pelo Código do Direito de Autor e Direitos Conexos e demais legislação aplicável, toda a cópia, parcial ou total, deste documento, nos casos em que é legalmente admitida, deverá conter ou fazer-se acompanhar por este aviso.

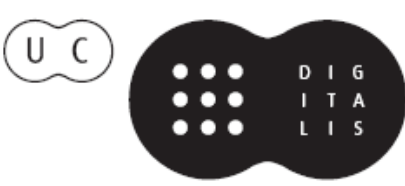


Maria Manuel Borges

Elias Sanz Casado

Coordenação

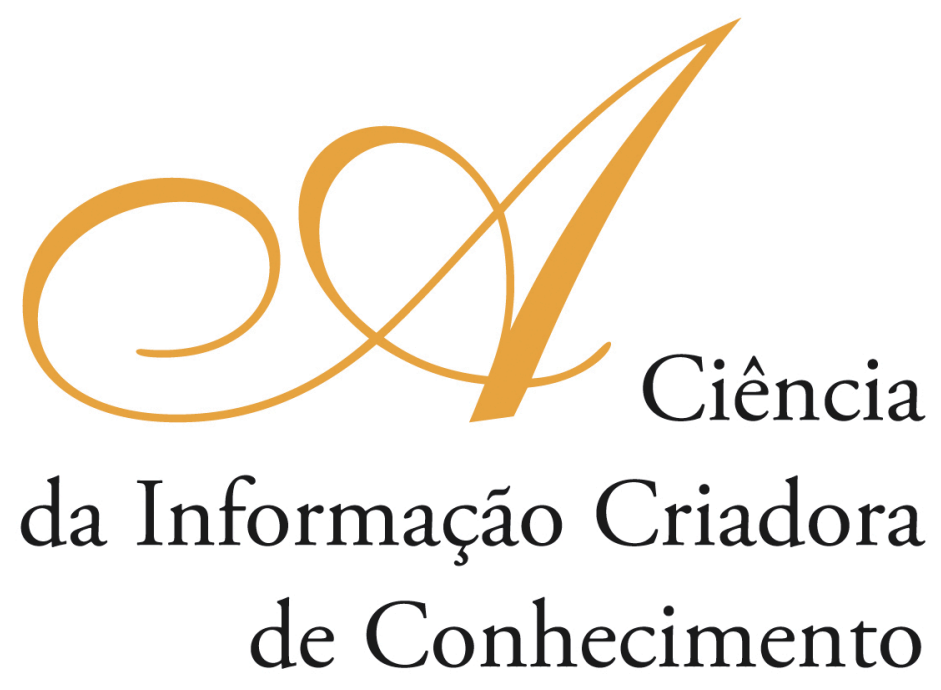

Vol. I

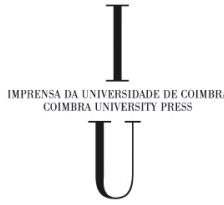

- COIMBRA 2009 


\title{
Atuaçấo da ABEBd na eVolução do currículo \\ de graduação em Biblioteconomia no Brasil, ENTRE OS ANOS 1967 E $2000^{I}$
}

\author{
Francisco das Chagas de Souza \\ Universidade Federal de Santa Catarina (Brasil)
}

\section{Resumo}

Trata de parte de estudo feito com o propósito de buscar a compreensão das açôes de política institucional e acadêmica da Associação Brasileira das Escolas de Biblioteconomia e Documentação - ABEBD. Teórica e metodologicamente, fez-se escolhas coerentes com uma abordagem sócio-histórica. Essa perspectiva se ancora na teoria con(figuracional) de Norbert Elias; na teoria construcionista-interacionista de Berger e Luckmann e na teoria das representaçóes sociais de Serge Moscovici. Para a coleta e tratamento de dados foi adotada a técnica do Discurso do Sujeito Coletivo. Os dados foram obtidos em documentos produzidos pela Associação, acrescentado de entrevistas, que gerou a parte principal do material coletado. Os objetivos foram: a) Avaliar as iniciativas para aperfeiçoamento do ensino e das condiçóes de ensino de Biblioteconomia no Brasil. b) Analisar os argumentos encontrados na documentaçáo e que servem como fundamentos sócio-históricos. c) Identificar os canais principais para os quais se dirigiam as iniciativas. d) Conhecer as representaçôes dos dirigentes da ABEBD sobre o impacto que a entidade proporcionou na evolução do currículo de graduação em Biblioteconomia no Brasil. Após a análise do material coletado obteve-se um Discurso do Sujeito Coletivo. Ele permite que se perceba a existência de impactos positivos, quando se olha para os resultados que foram obtidos em relação às conseqüências da articulação das escolas brasileiras com as demais escolas situadas nos países do MERCOSUL.

\begin{abstract}
This part of study done for the purpose of seeking an understanding of the actions of political and academic institutions of the Associação Brasileira de Escolas de Biblioteconomia e Documentação (Brazilian Association of Schools of Librarianship and Documentation) - ABEBD. Theoretically and methodologically, it was made choices consistent with a socio-historical approach. This perspective is anchored in the theory from Norbert Elias, in theory of Berger and Luckmann and the theory of Serge Moscovici. For the collection and processing of data was used the technique of the Discurso do Sujeito Coletivo (Collective Subject Discourse) - DSC. The data were obtained from documents produced by the Association, added interviews, which generated the bulk of the material collected. The objectives were: a) assess the initiatives for improving the conditions of teaching and teaching of librarianship in Brazil. b) Examine the
\end{abstract}

${ }^{1}$ Elaborado com base no Relatório da Pesquisa "O impacto da atuação da ABEBD na evolução do currículo de graduação em Biblioteconomia no Brasil, entre os anos 1967 e 2000”, desenvolvida com apoio financeiro do CNPq/MCT/Brasil (Processo no 473200/2006-6, de outubro de 2006 a setembro de 2008). 
arguments found in the documentation and that serve as social-historical reasons. c) identify the main channels for which the initiatives were addressed. d) Knowing the representations of the leaders of ABEBD the impact that the authority provided in the development of the curriculum of studies in librarianship in Brazil. After analysis of the collected material obtained is a Discourse of the Collective Subject. It allows to realize the existence of positive impacts, when you look at the results that were obtained for the joint consequences of Brazilian schools with other schools located in the Mercosur countries.

\section{Introdução}

Neste "paper" apresenta-se parte dos resultados de etapa de um programa de pesquisa que se está realizando nos últimos anos, visando ao aprofundamento da análise e avaliação sobre o alcance das açóes da Associação Brasileira de Escolas de Biblioteconomia e Documentação (ABEBD); durante o período em que essa entidade permaneceu ativa, isto é, até meados do ano de 2001. Liderado pelo autor deste artigo, esse programa produziu vários trabalhos, dos quais alguns estão apresentados nas referências ao final (Souza, 2006a, 2006b, 2008, 2009). Busca-se compreender a liderança exercida pela entidade quanto aos encaminhamentos realizados, acerca do ensino de Biblioteconomia e da formação de Bibliotecários no Brasil. Tal esforço vem do fato de que permanece pouco estudado o impacto que a atuaçáo da ABEBD propiciou à evoluçáo curricular do ensino de Biblioteconomia; considerando, sobretudo, as finalidades constantes em seu estatuto inicial, de 1967, em seu segundo estatuto, de 1977 e no terceiro, de 1987, os quais postulam, entre outros aspectos, a responsabilidade institucional de: "planejar o desenvolvimento da Formaçáo Biblioteconômica" e "sugerir o estabelecimento de requisitos mínimos do regime de estágio e de bibliotecas-laboratório".

Nesse sentido, os objetivos mais amplos do programa de pesquisa se expressam como: a) Avaliar as iniciativas realizadas pela ABEBD para o aperfeiçoamento do ensino e das condiçóes de ensino de Biblioteconomia no Brasil, desde sua criação, 1967, até a sua extinção não jurídica em 2001, tomando como fonte de dados a documentação primária produzida pela entidade; b) Analisar os argumentos apresentados no conteúdo dessa documentação, visando interpretá-los como fundamentos de caráter sócio-histórico para a tomada dessas iniciativas; c) Identificar os canais principais para os quais se dirigiam essas iniciativas documentadas e suas respostas documentadas e perspectiva de envolvimento previsto; d) Conhecer, através de contato direto e pessoal, as representaçóes dos dirigentes da $\mathrm{ABEBD}$ sobre o impacto que a entidade proporcionou na evoluçáo do currículo de graduação em Biblioteconomia no Brasil.

\section{Bases teóricas e metodológicas}

A pesquisa referente a esta etapa, coerente com o programa em que se insere, foi desenvolvida tomando como característica principal a abordagem qualitativa e desdobrou-se em várias açóes envolvendo técnicas de coleta de dados documentários e orais, no segundo caso com o uso da entrevista.

Diante do seu objeto e dos seus objetivos propostos, foi adotada a análise de discurso. Para isso, foram empregadas técnicas e instrumentos apropriados à realização 
de uma coleta de dados adequada a uma análise e interpretação sócio-histórica. Sob essa perspectiva teórica concebe-se que os fenômenos encadeiam um processo e se modificam ao longo do tempo criando novas figuraçóes na sociedade (Elias, 1993, 1994, 1998, 2001), e por ser movimento que envolve as interaçóes entre os indivíduos produz uma construção permanente da realidade (Berger; Luckmann, 1985).

Adotou-se esse caminho, pelo entendimento de que os discursos obtidos, tanto inscritos em documentos formais quanto nos depoimentos pessoais, refletiriam mais de três décadas de funcionamento da ABEBD. Também, o desenvolvimento do estudo dependia do tratamento textual, de documentos escritos e das falas captadas, e a sua interpretação, em busca de possíveis representaçôes sociais neles contidas. Isso implicou na busca da percepção de como indivíduos e sociedade interatuam e de como, nessas circunstâncias da realidade socialmente construída, os indivíduos movemse continuamente produzindo representaçóes. Tal direção leva a se perceber como as pessoas colaboram com a constituição das figuraçóes aparentemente novas, sobretudo fruto do pensamento produzido no âmbito do senso comum (Moscovici, 2004).

Como parte do desenvolvimento do estudo, formou-se um agrupamento de discursos, os quais foram submetidos à análise a partir da perspectiva de que discursos são constituídos por partes. No caso, empregou-se a técnica do Discurso do Sujeito Coletivo (DSC), pela qual, dessas partes, também denominadas de figuras metodológicas pelos criadores da técnica adotada, selecionou-se: expressóes-chave (EC) e idéias centrais (IC) (Léfevre; Léfevre, 2003). As Expressóes-chave (EC) são pedaços, trechos e transcriçóes literais do discurso obtido que em geral estão relacionadas com a pergunta da pesquisa e as Idéias Centrais (IC) são figuras ou termos criados para determinar a(as) expressão(óes) que concentra $(\mathrm{m})$ com fidelidade a intenção do sujeito que realizou o discurso; é uma forma de expressar indícios e serve para permitir a reunião do que é aproximadamente semelhante entre os conteúdos das ECs.

No estudo que deu origem a este "paper", a preferência pelo instrumental escolhido, sustenta-se em que o uso da "narrativa estimulada" é um relevante recurso metodológico. Associado a isso, entendeu-se que técnicas interpretativas de discursos permitem que se parta da compreensão de que os indivíduos constroem e reconstroem permanentemente a sociedade; contribuindo com a sua materializaçáo institucional, sob a forma de escolas, associaçóes profissionais, sindicatos e o próprio estado. Desse modo, buscouse em Araya Umaña a noção de perspectiva processual da representação, por esta ter mais adequaçáo com os procedimentos empregados. Segundo aquela autora: "para acceder al contenido de una representación, el procedimiento clásico utilizado [...] es la recompilación de un material discursivo producido en forma espontánea (conversaciones), o bien, inducido por medio de entrevistas o cuestionarios. Los discursos cristalizados en obras literarias, soportes periodisticos, grabaciones de radio pueden ser también objeto de analisis.” (Araya Umaña, 2002, p. 49)

\section{Procedimentos empregados}

$\mathrm{Na}$ realização da coleta e tratamento dos dados foram considerados os aspectos contextuais que pudessem revelar as circunstâncias de existência e manutenção dos fundos documentais; suas condiçóes de acesso e uso, as possibilidades de empréstimo 
e cópia, os meios para o deslocamento dos documentos ou do pesquisador para a coleta dos dados, assim como a facilidade de contato e diálogo com os ex-dirigentes da Associação.

Acerca da existência e manutenção dos fundos documentais, cabe assinalar que a ABEBD foi uma entidade nacional, sem sede fixa e com dirigentes oriundos de quaisquer lugares do país onde houvesse curso de Biblioteconomia. Embora, inicialmente constasse de seu estatuto que sua sede seria em Belo Horizonte, essa deliberação veio a ser alterada. Assim, o caráter rotativo da origem de seu presidente, que faz todo o sentido em face da constituição da entidade, fez com a que a Associação tivesse ao longo de seus anos de existência ativa 12 presidentes, tendo sede provisória nas localidades onde eles se encontravam: 1967-1969 - Belo Horizonte - MG; 1969-1971 - São Carlos - SP; 1971-1973 - Niterói - RJ; 1973-1975 - Salvador - BA; 1975-1978 - Campinas - SP; 1978-1982 - Florianópolis - SC e Rio de Janeiro - RJ; 1982-1988 - Recife -PE; 1988-1991 - Porto Alegre - RS; 1991-1995 - Marília - SP; 1995-1998 - Porto Alegre - RS e 1998-2000 - Campinas - SP.

Esse fato provocou uma dispersão na documentação da Associação, da qual é possível encontrar-se partes em originais e cópias em diferentes lugares sem uma unidade de tratamento. Embora mantidas com o máximo de cuidado, conforme as condições que dispóem cada um dos guardiôes dessa memória; tal documentação está sujeita ao desaparecimento, o que torna quase insuportável o pensamento de que poderia ser esse o destino da memória de uma associação de escolas e de professores de Biblioteconomia e Documentação.

Quanto às condiçốes de acesso e uso da documentação destaque-se que é muito restrito, a depender de contato com alguns dos ex-presidentes, posto que há material guardado tanto na residência quanto em sala-ambiente de trabalho de ex-presidentes, assim como há uma parte digitalizada e mantida no portal da Associação Brasileira de Ensino em Ciência da Informação (ABECIN). Desse modo, pelo próprio processo de armazenamento, em geral, em caixas e envelopes pouco padronizados, sem série documental claramente definida, com maior ou menor quantidade de pó, ainda que o acesso geral seja fornecido, o uso torna-se pouco prático.

No que toca às possibilidades de empréstimo e cópia da documentação, a própria condiçáo de interinidade das diretorias e de sede da entidade, faz com que seja uma operação informal.

Os dados documentais para a pesquisa foram captados no período de 2006 e 2007 . As entrevistas, especificamente foram realizadas em 2007, em parte auxiliadas pelas novas informaçóes obtidas através dos documentos anteriormente compulsados.

No desenrolar do processo de gravação das falas e sua posterior transcrição, em primeiro lugar, antes da apresentação dos questionamentos, solicitou-se verbalmente a cada uma das pessoas entrevistadas a devida permissão para a gravação de suas respostas. Para essa coleta foi empregado um sistema de gravação eletrônica, o Digital Voice Recorder W-10, da Olympus, representado por um equipamento de registro sonoro e um software de audição legível em windows xp. O processo de transcrição foi manual, com a audição das entrevistas e registro, inicialmente, em papel. Essa transcrição gerou o material que veio a ser submetido à análise com a utilização do Instrumento de Análise do Discurso (IAD), um recurso da técnica do DSC, conforme a terminologia empregada por seus criadores. 
Os dados documentais foram coletados a partir de um questionário. Com ele foram obtidos os informes acerca das iniciativas tomadas, das relaçóes institucionais da entidade, bem como dos fundamentos definidos para a condução dessas açóes. E os dados de entrevista pessoal foram coletados a partir de um formulário próprio. Através do uso deste instrumento estimulou-se o interlocutor a expressar livremente seu pensamento avaliativo acerca dos impactos que a entidade produziu na evoluçáo do currículo de graduação em Biblioteconomia no Brasil. Os dados, após a coleta, foram também transpostos para o IAD.

$\mathrm{Na}$ etapa seguinte, foi construído o Discurso do Sujeito Coletivo (DSC). Inicialmente, todos os discursos produzidos para cada questão geraram o DSC de cada pergunta e no final elaborou-se o DSC geral. Nele, que se apresenta como o resultado do estudo, foi consolidado o conjunto dos discursos (documentais e pessoais) examinados e feita a interpretação que permite o conhecimento do impacto, e suas razóes e a origem dessas razóes. O DCS geral, consolidado no resultado apresentado a seguir, traz um discurso em primeira pessoa e acentua uma composição das falas na ordem histórica dos fatos relatados nas entrevistas.

\section{Resultado}

Esse DSC permite observar que, de certo modo, a noção do currículo somente como lista de disciplinas foi superada. Mas não ficou evidente a superação da limitação de uma educação técnica.

Em 1967, nós estávamos ainda com aquele primeiro currículo de 1962 e a criação da $A B E B D$ foi fundamental porque antes eram iniciativas de pessoas. A profissão havia sido regulamentada também em 1962. Naquele momento, o professor não tinha vinculação de contrato de trabalho em carreira docente. Não havia Projeto Pedagógico, existia uma idéia de formar o aluno com perfil tal e tal. E era muito difícil e era novo falar de pesquisa na graduação. A intenção era promover e fortalecer a classe, os professores. Naquela época, a atividade associativa e acadêmica estavam muito juntas, porque eram os professores que eram a liderança. A atividade da corporação estava dentro da academia, fertilizando o efeito multiplicador. A existência da ABEBD foi importante para que as escolas e os educadores se enxergassem um pouco no contexto brasileiro, a partir da nova realidade: uma realidade das escolase, principalmente, como fórum para aglutinar, socializar as inquietaçôes, preocupaçóes e propostas da área, ser âncora para que essas discussóes ocorressem, ser porta voz ,ser um espaço comum. A ABEBD teve um grande envolvimento com a concepçáo do novo currículo mínimo. Foi a grande idealizadora do movimento de revisão, de reformulação, de um repensar do currículo. No currículo de 1982, houve um primeiro papel da $A B E B D$ e houve uma participação externa, embora nem tudo que está no currículo de 1982 reflita a concepçáo da ABEBD, ela ofereceu uma contribuição muito grande. O currículo de 1982 promoveu uma pequena diminuição da parte técnica e aí as pessoas começaram a voltar um olhar mais para a área de administração e houve, realmente, uma pequena evolução aí. Ou seja, deu-se a saída da catalogação, da classificação como núcleo central da biblioteconomia. A existência da ABEBD trouxe a vontade de inserção de mais disciplinas no programa, como a Psicologia, a 
Antropologia e de ser trabalhada a metodologia da pesquisa; a presença de um docente mais qualificado do que somente o profissional bibliotecário. Isso trouxe qualidade ao ensino. Enquanto proposta teórica, de modelo de ensino, houve uma contribuiçáo importante. Em termos práticos, o resultado, ou resposta aos esforços da ABEBD, foi diferente, em diferentes escolas, pelas suas condiçôes locais, lideranças locais, segundo os processos de acomodação possíveis. No entanto, como parte dessa trajetória, pode-se dizer que nós perdemos, o que no antigo currículo chamávamos de Evolução do Pensamento Filosófico e Científico e se introduziu a Lógica, como disciplina instrumental. Foi ótimo a introdução da Lógica, mas não poderíamos ter perdido a disciplina Evolução do Pensamento Filosófico e Científico. Esse tipo de reflexão sobre ganhos e perdas permeava muitas discussóes. Também, pode-se ver que o currículo de 1982 foi aprimorado e implementado por pessoas de fora da área, o de 1962 não fora assim. O currículo de 1982 foi produto de discussão, de movimento dos cursos, com muito mais profundidade. No relatório do ENEBCI de 1986é onde a gente vai ver porque o tema foi o currículo mínimo. Nesse primeiro Encontro Nacional de Ensino de Biblioteconomia e Documentação, o tema foi pensar o novo currículo. A partir dele, se desdobraram as discussóes sobre a figura do docente, a capacitaçáo didático-pedagógica, reforçando a modificação da atuação apenas conteudista. A ABEBD, fez de 1989 a 1992, estudo curricular. Em 1991, há o Encontro cujo tema foi a capacitação pedagógica do docente.Mas nas reuniôes da ABEBD, nos eventos, essa questão da capacitação ficou bastante presente. A partir de certo momento, houve um perfil um pouco mais acadêmico, mas é principalmente porque a ABEBD e a ANCIB tiveram um diálogo mais próximo. Além disso, nos seminários didáticopedagógicos, a gente sempre trabalhou procurando melhorar o nosso desempenho, a carreira profissional e a relaçáo com o aluno em sala de aula. Foi feito em 1992 um Encontro Nacional de Ensino, durante 3 dias, discutindo quais as perspectivas para a carga pedagógica do docente, quais as perspectivas que o docente tinha para se atualizar, como se dava a relação professor e aluno.Também, tínhamos a organização por grupos regionais, com coordenaçôes regionais e todos os grupos passaram a funcionar, a interagir desenvolvendo seminários locais. Nesse período, a gente fez um projeto e conseguiu a primeira etapa do Projeto "Perspectivas para o ensino de graduação em Biblioteconomia no Brasil”. Esse projeto dividia o Brasil nas 5 áreas curriculares da Biblioteconomia e propunha fazer 5 seminários para trabalhar com professores dessas área, em diferentes regiōes.O primeiro, foi em novembro de 1993, em Belém, do Pará. Então, foi uma idéia de trabalhar por área curricular, nessas partes do país, já que estatutariamente os ENEBCIs tinham que ser no eixo Rio, São Paulo, Belo Horizonte e Brasília. Nessa década, foi um avanço a companhia que se deu entre as escolas brasileiras e as dos países do Mercosul. Produziu-se um currículo mais debatido, foi satisfatório. Era aquilo que a gente estava pensando. O TCC sempre estar relacionado com a pesquisa, o incentivo para que o professor faça pesquisa, para ele entender como se dá esse processo, se produz o conhecimento, para que haja o incentivo à busca de informação, para que se assimile a postura do pesquisador.Em 1998 em Sáo Carlos - SP, tivemos um Encontro para discutir o impacto da LDB no currículo. No final dos anos 90 nós tivemos a definição daquelas 4 grandes áreas que o currículo do Mercosul enfocou: 1 - Fundamentos de Biblioteconomia e Ciência da Informação; 2 - Organização e Tratamento da 
Informação; 3 - Recursos e Serviços de Informação; 4 - Gestão da Informação. E essa talvez seja a melhor coisa que tenha acontecido nesse currículo, que foi amoldar o pensamento para essas áreas de todos que não tinham um pensamento maior sobre a profissão de bibliotecário, embora tudo tenha caráter muito introdutório.A grande área passou a ser a gestão, e há cursos que têm um número significativo de disciplinas na área de gestão. Também vê-se que há desequilíbrio entre o volume de conteúdos ministrado na área 1 (Fundamentos de Biblioteconomia e Ciência da Informação) em relação à área 3 (Recursos e Serviços de Informação voltados ao usuário), porque existe um descasamento entre elas. Talvez uma solução seja uma disciplina de usuário. Em síntese, a ABEBD teve algumas fases: de início era o sentido de fortalecer corporativamente a profissão, as escolas, e estabelecer os nossos limites e dar visibilidade. Depois houve maior interação externa, com a pós-graduação, o ensino com pesquisa, já buscar o avanço qualitativo, inclusive a expansão internacional, com o Grupo do Mercosul. A intenção sempre foi mostrar para o docente que a ABEBD estava preocupada com ele e tentar trazer discussóes que permitissem a esse docente se ver naquele meio. Percebe-se que houve uma evoluçáo curricular. No grupo já percebia o outro. Mas não foi a evoluçáo desejada, nem com equilíbrio e nem comunicação entre as áreas, porque elas continuaram isoladas.Parece que há um grande problema, o discurso é pró-mudança, mas a ação é para que continue tudo aquilo que nós sempre fizemos e que acreditávamos que estava bom. Há muita deficiência; muda o rótulo, faz maquiagem, numa situação mais de aparência de que, realmente, de redefinição. Nesse período, como dirigente, a preocupação maior era com a continuidade das açóes, procurando fazer e mostrar uma interação maior com a pósgraduação era uma estratégia para que nos olhassem, e a partir disso deu para fazer algumas discussóes direcionadas para a presença da pesquisa, a importância do projeto de TCC como iniciação científica, o ensino com pesquisa, e isso aí abriu um canal para a interação com a pós-graduação. O esforço foi em manter o que estava consolidado. Manter o Seminário Nacional de Avaliação Curricular; reforçar a regionalização da $\mathrm{ABEBD}$, para democratizar sua atuação; integrar aquelas escolas que tinham pouca ou nenhuma tradição acadêmica. Também buscou-se uma mudança no foco. Até então a grande preocupação estava centrada no currículo, e canalizamos a reflexão para duas perguntas básicas: a) Quem somos nós? b) Quem nós pretendemos formar? Se tivéssemos uma reflexão sobre quem nós pretendemos formar, então, o currículo seria um reflexo e não o contrário. De outro lado, não dá para dizer que isso era realizado como ação planejada, a partir de planos de ação pré-concebidos. $\mathrm{O}$ que permitiu que isso acontecesse foi uma reflexão que permeou a $\mathrm{ABEBD}$ por muitos anos, centrada no profissional, sobre qual era o profissional que nós queriamos criar. Nos documentos da $\mathrm{ABEBD}$, das gestóes anteriores, a gente percebe aquela questão de náo idolatrar o mercado. Existe um documento que diz, vamos formar um profissional que possa antecipar o mercado, ir além do mercado, mas, náo negar o mercado. Como atividade planejada, não se fez, não se alcançou. E os resultados são aleatórios. Olhando o conteúdo curricular, há um descolamento entre o que é pesquisado, ministrado e a realidade. $O$ que se vê é que o movimento em torno da elaboração das diretrizes curriculares foi um movimento em que a ABEBD teve uma ação política fortíssima e provavelmente foi a primeira vez que a Comunidade docente de Biblioteconomia fez um movimento político, para fazer valer aquilo que 
ela já havia discutido e acordado. A ABEBD sempre foi uma associação de docentes; ela transcende a dimensão institucional; é um grupo de pessoas preocupadas com determinadas questóes. Ao olhar-se para as atas das reunióes do Conselho Diretor vê-se um grupo que se mantém, independentemente de estar ou não na direção de cursos ou escola. A Associação é movida pelo voluntarismo, a partir da capacidade agregadora de algumas pessoas. Olhando para esses dois momentos, percebe-se que a Cléa Dubeux e a Lourdes Gregol foram as presidentes da Associação que encerraram uma época, um ciclo, em que os professores vinham do mercado de trabalho, da prática para a escola, em que a Pós-graduaçáo era muito incipiente. Depois, veio um segundo momento em que a $A B E B D$ aproximou-se mais da academia.

\section{Interpretação do resultado obtido}

Nessa breve interpretação, pode-se partir da idéia de que o DSC exposto constitui uma expressão de tudo o que está presente nas falas dos dirigentes entrevistados. Não quer dizer que nele está contido apenas o que foi mais destacado, o que teve mais ênfase. Nele está tudo o que apareceu em todas as falas, pelos conteúdos que nelas foram contemplados, a partir das questóes apresentadas na entrevista. Trata-se de uma narrativa a ser examinada.

Conforme Bastos (2008, p. 95) narrativas devem ser compreendidas como construção social mais que como uma representação do que aconteceu, pois nós construímos as estórias que contamos em função da situação de comunicação (quando, onde e para quem contamos). Ainda que se possa ver no DSC acima representaçóes, isso não significa que se trata de uma memória congelada na mente do entrevistado. Pois, não se pode dizer que o conteúdo dos relatos coletados foi modificado em relação aos fenômenos levados a questionamento; pode-se talvez dizer que eles foram submetidos a juízo, enquanto eram repassados ao interlocutor. Sobre isso, a mesma autora anteriormente citada (Bastos, 2008, p. 95) observa, que a situação de comunicação, leva a que se utilize "de filtros afetivos e culturais e do que estamos fazendo ao contar uma estória". Nesse sentido, Bastos (2008, p. 94) aponta que: "As narrativas não são mais consideradas como representaçóes diretas e transparentes de eventos passados, mas sim como recontagens seletivas e contextualizadas de lembranças de eventos."

Deve-se considerar, portanto, que se torna significativo levar em conta que os entrevistados falaram de um momento passado em que se desempenharam como protagonistas de um lugar de atuação - a Presidência da ABEBD. No momento da entrevista, não estava implicado apenas o objeto questionado ( $O$ impacto da atuação da ABEBD na evoluçáo do currículo de graduação em Biblioteconomia no Brasil, entre os anos 1967 e 2000) sob o foco de interesse da pesquisa mas, certamente, também cada protagonista que tratava de recontar as lembranças dos eventos em que esteve envolvido, pois era ele ou ela parte do próprio desenrolar daqueles eventos. Tal circunstância, não estabelece um seguro distanciamento emocional e afetivo em relação ao conteúdo expresso.

Em síntese, segundo os dirigentes entrevistados, o que de mais significativo pode-se perceber da atuação da ABEBD na evolução do currículo de graduação em Biblioteconomia no Brasil, entre os anos 1967 e 2000? Abaixo, mostram-se algumas 
expressóes destacadas do DSC e tenta-se confrontá-las com o contexto brasileiro imediatamente próximo em termos históricos, sociais, econômicos e políticos.

No DSC há a afirmação: “Antes as iniciativas eram de pessoas”. A isso pode-se relacionar que em termos de educação as iniciativas tomadas no ensino de Biblioteconomia ainda centravam em algumas personalidades que exerciam a liderança de fazer o ensino fluir. Também havia o fato de que o ensino universitário de massa ainda náo era o modelo predominante. $\mathrm{O}$ quadro econômico brasileiro ainda configurava um país predominante rural e com pouca exigência em torno de uma infra-estrutura urbana que inserisse demandas significativas de gestão de informação. A condição política, também, apontava para uma paralisia das iniciativas de fomento cultural com a ativação de polos culturais dinâmicos em torno de bibliotecas públicas. Do mesmo modo, o modelo de educação básica focava-se na aula do professor, que era feita predominante pela preleçáo. Sobretudo, o ambiente político ao cercear quase todas as iniciativas cidadãs, tornava mesmo a ação coletiva, sob a forma de uma associação, refém do medo de contrariar as verdades do governantes de plantão.

Outra afirmação no DSC é: “O professor não tinha vinculação de contrato de trabalho em carreira docente". Naquele momento histórico eram poucos os professores profissionais. O testemunho de Berlinck (2001, p. 46), contemporâneo dessas circunstâncias, ilumina esse fato. Diz: "Quando iniciei meus estudos universitários [1958], a Escola de Sociologia e Política de São Paulo estava passando, com toda a universidade brasileira, por uma grande transformaçâo. Seu corpo docente estava deixando de ser diletante e começando a se profissionalizar. Até entáo, quem ensinava na universidade eram profissionais que ganhavam a vida fora e se beneficiavam do prestígio que a posiçáo de professor universitário lhe concedia. [...] Por volta de 1955, já começava a haver, no Brasil, um conjunto de pessoas que pretendia viver do trabalho de professor universitário. Para isso, pretendiam que o cargo de professor fosse em tempo integral e dedicado à docência e à pesquisa. Essa mudança, que começava a ocorrer, implicava uma grande transformação, pois até então a universidade era um trampolim para a política $e$ para cargos particulares e públicos de prestígio e alta remuneração. Além disso, ser professor universitário era uma atividade prestigiosa, mas com ganhos marginais." (grifou-se)

No DSC consta: "Não havia Projeto Pedagógico, existia uma idéia de formar o aluno com perfil tal e tal". É um dado histórico brasileiro que, nessa época, a universidade constituía-se ainda como um projeto em início de implantaçáo. O primeiro grande conjunto de universidades criado no Brasil o fora do final dos anos 1950 para o inicio dos anos 1960. Os cursos funcionavam com um nível significativo de precariedade e se medidos pelos padróes posteriores eram muito frágeis; eram livrescos por um lado e, por outro, estavam em instituiçóes onde o investimento em bibliotecas sempre era mínimo. A noção de projeto pedagógico era substituída pela de currículo, entendido como um rol de disciplinas. Isso se aplicava também ao ensino de biblioteconomia.

Também está presente no DCS: "Era muito difícil e era novo falar de pesquisa na graduaçáo". Naquela conjuntura social, a noção de pesquisa acadêmica, como parte do processo de formação na graduação, era muito nova no país e ainda fortemente associada à pesquisa físico-experimental. A existência do então Conselho Nacional de Pesquisa $(\mathrm{CNPq})$ era nova. $\mathrm{O}$ órgão era de criação recente, pois fora implantado em 1951, visando a inserir o Brasil na discussão internacional em torno da investigação no campo da energia atômica (A proposta...). A então Campanha de Aperfeiçoamento de 
Pessoal do Ensino Superior (CAPES), instituída em 1951, (A educação...), estava ainda distante de sua futura missão de agência de fomento e regulação da pós-graduação. Segundo Salomon (2000, p. 125), também nas ciências humanas e sociais, campo onde se insere nas várias concepçóes existentes a Biblioteconomia, naquela época, ainda era uma novidade o seu estatuto científico no âmbito internacional.

À propósito do caso brasileiro, quanto à instalação de um espaço acadêmico para a produção de pesquisa e conhecimento, estava-se buscando a produção de uma legislação que desse feição à pós-graduaçáo no país. Esse instrumento veio a se objetivar no Parecer 977 da Câmara de Ensino Superior (CES) do então Conselho Federal de Educação, de 03/12/1965 (Parecer...). Também foi em 1965, através do Decreto-Lei $\mathrm{n}^{\circ} 53$, que a universidade brasileira foi caracterizada oficialmente como instituição de ensino e pesquisa. (grifou-se).

Também está apontado no DSC: "A intençáo era promover e fortalecer a classe, os professores". Nisso, certamente, persistia a visão corporativa de fortalecimento do Grupo docente. Como era ainda expressivo o entendimento da necessidade de associação que reunisse bibliotecários, esse entendimento extravasaria no sentido de haver a associação das escolas, de forma a promover os docentes. Essa idéia estava alinhada ao movimento anterior dos bibliotecários, em torno da criação de estruturas que os representassem, como as associações de profissionais, a federação de associaçóes e o conjunto de ordens ou Conselhos profissionais.

No DSC está presente: "A atividade associativa e acadêmica estavam muito juntas, porque eram os professores que eram a liderança”. Parecia natural que a experiência organizativa passasse a atender mais aos interesses do grupo nascente - o dos docentes - que tinha possibilidade de crescer, pois se ampliava o potencial econômico do país. Nisso já havia todo o treinamento que se foi acumulando desde a primeira Associação de profissionais, criada com a participação de Rubens Borba de Moraes em 1938 (Bandeira, 2007, p. 49; Moraes, 2001).

Foi afirmado no DSC que a ABEBD "Era a forma de se assumir um novo olhar para o contexto brasileiro: o olhar das escolas e dos educadores, a partir de uma nova realidade: uma realidade das escolas".

A documentação recolhida mostra que houve uma grande contribuição do trabalho da Associação para a implantação do currículo de 1982, a partir mesmo do fato de que esse esforço teve início em 1971. Nesses onze anos de movimento por um novo currículo a Associação chegou, a duras penas, a uma Proposta. Vê-se que a concepção da ABEBD foi alterada; que houve reaçóes com críticas severas aos Seminários para otimização do currículo, o que leva a Presidente da ABEBD na ocasiáo tentar dialogar, argumentando pela fé, no sentido de que haveria com o novo currículo uma melhor escola de Biblioteconomia no Brasil. A documentação mostra, por outro lado, que havia personalização de etapas do trâmite e uma postura de aparente ingenuidade, que se manifesta em vários textos. Também, exibe que houve a suspeita de interferências de lideranças bibliotecárias para redefinir partes do documento atinente ao novo currículo, durante sua tramitaçáo legislativa. $O$ fato de o relator ter determinado o mínimo de 2.500 horas para o total de horas aulas do Curso, com o argumento de que isso melhoria o reposicionamento dos bibliotecários vinculados ao Serviço Público Federal (SPF) do Brasil veio quase como um argumento que justificaria a acomodação da $A B E B D$ à situação, e a uma aceitação de que sua força poderia ser menor do que 
a de algumas pessoas que teriam interferido "negativamente", segundo pareceu em certo momento no andamento do processo.

No DCS manifesta-se: “O currículo de 1982 foi aprimorado e implementado por pessoas de fora da área, o de 1962 náo fora assim”. Efetivamente, houve a participação de pessoas de fora da área. Em um dado momento, a sede da Associação foi levada para dentro do Instituto Brasileiro de Informação Científica e Tecnológica (IBICT), por curto tempo, embora, mas com propósitos claros da presidente de então, como documentado. Igualmente, há documento, que dá conta de que os participantes do Seminário de Currículo, realizado em Brasília, de 5 a 9 de maio de 1980, realizado sob o patrocínio da Organização dos Estados Americanos (OEA), resolveram, por proposição daquela Presidência, organizar um grupo de trabalho para concluir os estudos desenvolvidos visando a reformulação do Currículo Mínimo de Biblioteconomia. Dentre os membros listados consta o nome do Professor Aldo de Albuquerque Barreto, cujos estudos sempre foram direcionados para a Ciência da Informação, como fundo teórico para a Informação Científica e Tecnológica. Certamente, esse é um viés que tende a ampliar um certo distanciamento no interesse para as questóes sociais da Biblioteconomia, representado por estudos e ensino dirigidos para as questóes institucionais (natureza, função, forma de operação, missão, etc) das bibliotecas públicas e escolares, de abordagem indiscutivelmente relevante, e que passaram a ser menos enfatizadas pelas escolas de Biblioteconomia.

Para a implementação do currículo de 1982, a ABEBD promoveu vários cursos, treinamentos e encontros de professores, levando à realizaçáo de discussóes sempre tendo como ponto de referência o novo Currículo Mínimo. A esse propósito, a documentação produzida pela $A B E B D$ mostra-se didática ou detalhada sobre alguns conceitos associados ao trabalho docente. Acrescente-se a isso que em documento da Presidente da ABEBD identifica-se consideraçóes pessoais, dir-se-ia de fundo histórico, acerca do ensino na área, fazendo a afirmaçáo de que por um problema cultural a escola de Biblioteconomia brasileira estava doente, fazendo com que a biblioteconomia brasileira fosse mal. Assim, as escolas precisariam ser tratadas, medicadas e acompanhadas para que pudessem reviver. Isso exigia um acordar dos professores. Contudo, seria preciso, conforme ela, não esquecer de que o ensino de biblioteconomia sempre foi passivo, apático, com a Escola ensinando a mesma coisa, ano após ano.

É evidenciado que, de 1989 a 1992, a ABEBD fez estudo curricular; que em 1992, promoveu um Encontro Nacional de Ensino, durante 3 dias, discutindo as perspectivas para a carga pedagógica do docente, as perspectivas que o docente tinha para se atualizar, como se dava a relação professor e aluno. Durante a década iniciada em 1991 houve significativa interação entre as escolas brasileiras e as demais existentes nos países do Mercado Comum do Sul da América do Sul (MERCOSUL). Isso levou à produção de um currículo resultante de mais debate, inserindo a idéia do Trabalho de Conclusão de Curso (TCC) sempre estar relacionado com a pesquisa. O objetivo da exigência do TCC era de que com isso haveria o incentivo para que o professor fizesse pesquisa de modo mais sistemático, de que pudesse entender como se produz o conhecimento e para que assimilasse a postura de pesquisador.

Outro momento destacável, é ver no final dos anos 1990 a definição das 4 grandes áreas que o currículo do MERCOSUL enfocou: 1 - Fundamentos de Biblioteconomia e Ciência da Informação; 2 - Organização e Tratamento da Informação; 3 - Recursos 
e Serviços de Informação; 4 - Gestão da Informação. Isso permitiu amoldar o pensamento para essas áreas de todos que não tinham uma idéia mais clara sobre a profissão de bibliotecário.

Mas o DSC revela um problema institucional. É que a despeito da evolução do currículo de Biblioteconomia no Brasil, as açôes realizadas pela ABEBD têm caráter mais individual e voluntário, resultante da iniciativa de alguns docentes. O senso coletivo esteve pouco desenvolvido, contribuindo para a persistência de muitos pontos frágeis na educação em Biblioteconomia no Brasil.

\section{Consideraçóes finais}

Pode-se dizer, no estágio atual da pesquisa, que a atuação da ABEBD na evolução do currículo de graduação em Biblioteconomia no Brasil, entre os anos 1967 e 2000:

1 - Levou a uma evolução curricular, mas não foi a evolução desejada, nem com equilibrio e nem comunicação especialmente entre as áreas curriculares, porque elas continuaram isoladas.

2 - Não se deu como ação institucionalmente planejada, contando com planos de ação pré-concebidos. Por isso, os resultados foram aleatórios. As escolas continuaram a atuar isoladamente.

3 - Que A ABEBD sempre foi uma associação de docentes; ela transcende a dimensão institucional; é um grupo de pessoas preocupadas com determinadas questóes. Ao olhar-se para as atas das reunióes do Conselho Diretor vê-se um grupo que se mantém presente, independentemente de estar ou não na direção de cursos ou escolas. A Associação é movida pelo voluntarismo, a partir da capacidade agregadora de alguns docentes.

4 - Que há um ponto alto na trajetória da ABEBD, que se dá no final dos anos 1990 e resulta nas Diretrizes Curriculares Nacionais do Curso de Biblioteconomia aprovadas em 2001. O destaque desta circunstância é que ela se expressa quase que como uma ruptura da postura de distanciamento das questóes politicas afirmadas nas finalidades da Associação quando de sua criação: o movimento em torno da elaboraçáo das diretrizes curriculares foi um movimento em que a ABEBD teve uma açáo política fortíssima e provavelmente foi a primeira vez que a Comunidade docente de Biblioteconomia fez um movimento político, para fazer valer aquilo que ela já havia discutido $e$ acordado. No momento em isso se dá, a ABEBD estava submergindo às dificuldades jurídicas de que foi vitima, justamente por conta da perda de documentos importantes para garantir a sua sobrevivência ativa. Sua postura foi corporativa, mas a essência do esforço realizado pode ter configurado uma contenda entre entendimentos sobre a relevância para a formaçâo do Bibliotecário, ou profissional da informação, de distintos conteúdos ou abordagens e de distintas relaçóes entre a Biblioteconomia e a Ciência da Informação.

\section{Referências bibliográficas}

A educação brasileira através dos tempos: 1951 - criação da CAPES (s.d). Recuperado em 15 de agosto de 2008, de http://www.tuneldotempo.inep.gov.br/1950/1951.htm 
A proposta de criação do CNPq (2000). Parcerias Estratégicas, 9, 182-195, out. 2000. Recuperado em 15 de agosto de 2008, de http://ftp.mct.gov.br/CEE/revista/Parcerias9/17revista9CNPq. PDF

Araya Umaña, S. (2002). Las representaciones sociales; ejes teóricos para su discusión. San José: FLACSO. (Cuaderno de Ciências Sociales, 127). Recuperado em 15 de agosto de 2008, de http://www.flacso.or.cr

Associação Brasileira de Educação em Ciência da Informação - ABECIN. Recuperado em 15 de agosto de 2008, de http://www.abecin.org.br/

Bandeira, S. P. (2007). O mestre dos livros: Rubens Borba de Moraes. Brasília, DF: Briquet de Lemos - Livros.

Bastos, L. C. (2008). Estórias, vida cotidiana e identidade - uma introduçấo ao estudo da narrativa. In: Caldas-Coulthard, C. R.; Scliar-Cabral, L. Desvendando discursos: conceitos básicos. (pp. 79-111). Florianópolis: Ed. UFSC.

Berger, P. I. \& Luckmann, Th. (1985). A construção social da realidade; tratado de Sociologia do conhecimento (6. ed.). Petrópolis: Vozes.

Berlinck, M. N. (2001). Elogio da universidade. In: Kantor; Maciel; Simões. A Escola Livre de Sociologia e Política - anos de formação 1933-1953 - depoimentos (pp. 45-56). São Paulo: Escuta.

Elias, N. (1993). Processo civilizador. (2 vol.)Rio de Janeiro: Jorge Zahar.

Elias, N. (1998). Sobre o tempo. Rio de Janeiro: Jorge Zahar.

Elias, N. (2001). A sociedade de corte. Rio de Janeiro: Jorge Zahar.

Elias, N. (1994). A sociedade dos individuos. Rio de Janeiro: Jorge Zahar.

Léfevre, F. \& Léfevre, A. M. C. (2003). O discurso do sujeito coletivo: um novo enfoque em pesquisa qualitativa (desdobramentos). Caxias do Sul: EDUCS.

Moraes, R. B. de. (2001). Da Semana de Arte Moderna à Fundação da Escola Livre: no calor de 1932. In: Kantor; Maciel; Simóes. A Escola Livre de Sociologia e Politica - anos de formação 1933-1953 - depoimentos. (pp. 127-133). São Paulo: Escuta.

Moscovici, S. (2004). Representaçôes sociais; investigaçôes em Psicologia Social. (2. ed.). Petrópolis: Vozes.

Parecer Sucupira de 1965: definição da Pós-graduação. INFOCAPES: boletim informativo (1999), Brasília, 7 (4), 37-51.

Salomon, D. V. (2000). A maravilhosa incerteza: ensaio de metodologia dialética sobre a problematização no processo do pensar, pesquisar e criar. São Paulo: Martins Fontes.

Souza, F. C. de. (2006a). O discurso construido no Brasil sobre o ensino de Biblioteconomia e Ciência da Informaçâo: processo sócio-histórico e seus desdobramentos, a partir dos documentos da ABEBD. (Relatório de Pesquisa). Florianópolis.

Souza, F. C. de. (2006b). O discurso sobre a educação em Biblioteconomia e Ciência da Informação: caminhos teórico-metodológicos para a compreensão. In: CUNHA, M. V. da; SOUZA, F. das C. de (org.). Comunicação, gestão e profissão: abordagens para o estudo da Ciência da Informação. (pp. 151-172). Belo Horizonte: Autêntica.

Souza, F. C. de. (2009). O ensino de biblioteconomia no contexto brasileiro: século XX. Florianópolis, Ed. UFSC.

Souza, F. C. de. (2008). O impacto da atuação da ABEBD na evolução do currículo de graduação em Biblioteconomia no Brasil, entre os anos 1967 e 2000. (Relatório de Pesquisa). Florianópolis. 